\title{
Electric Vehicle - Design and Implementation Strategies for the Power Train
}

\author{
Rui Santos ${ }^{(1)}$, Fernando Pais ${ }^{(1)}$, Carlos Ferreira ${ }^{(1)(2)}$, Hugo Ribeiro ${ }^{(1)(2)}$, Pedro Matos ${ }^{(1)}$ \\ (1) Escola Superior de Tecnologia do Instituto Politécnico de Tomar - Quinta do Contador - Estrada da \\ Serra, 2300 Tomar, Portugal, phone +351249328150 , fax: +351249328187 , e-mail: rui_s@zmail.pt, \\ fmpais@gmail.com,granchinho@ipt.pt
}

(2) Instituto de Telecomunicações, Lisboa Portugal, e-mail: cferreira@ipt.pt, hugo@ipt.pt

\begin{abstract}
The main objective of this paper is to describe the solutions encountered during the development of a power converter and its control for an electric traction vehicle.
\end{abstract}

This paper will focus on strategies and construction problems for the power converter, its protection and control of the power train.

Key words: Sliding mode control, electric vehicle, DC-DC converter.

\section{Introduction}

Negative environmental impact of the transportation sector imposes searching for alternative solutions to actual road vehicles. The vehicle presented in this paper is a prototype of a pure battery vehicle, which has the advantage of being a ZEV (zero emissions vehicle). The Fig. 1 shows the vehicle structure.

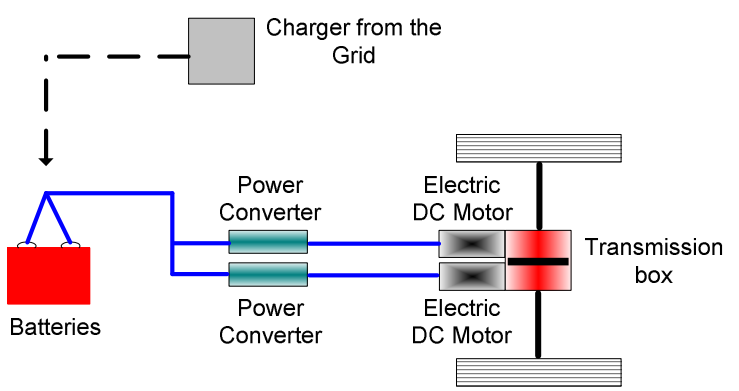

Fig. 1 - Structure of a pure battery electric vehicle

The Fig. 1 presents a possibility for an electric vehicle, with two motors, each one associated to one wheel, providing a system with two independent wheels drive. The motors power supply comes from two power converters (DC-DC converters) which are supplied by three $12 \mathrm{~V}$ batteries in a series connection. These batteries can be recharged from the mains network (grid).
The vehicle uses two $11 \mathrm{~kW} @ 48 \mathrm{~V}$ DC motors. The option of operate with low voltage motors is related with safety concerns; in counterpart this motors needed a high current value $(\approx 200 \mathrm{~A})$.

The Fig. 2 presents the building blocks of a DC motor current control system in closed loop. The objective of the DC-DC converter is to regulate the power delivered to the motor; the controller generates a square voltage waveform according the current error; the gate drive circuit commands the state of the switches of the DC-DC converter; the output filter reduce the ripple current in the motor to provide low losses.

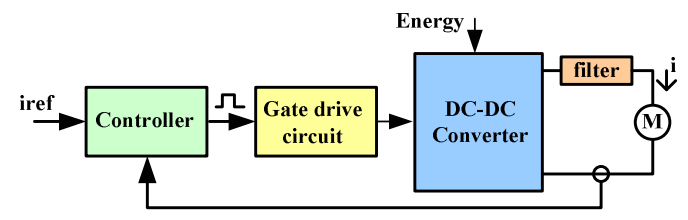

Fig. 2 - Building blocks of a DC motor current control system

The different blocks of Fig. 2 and their construction will be detailed along the paper. This work will focus on strategies and construction problems for the DC-DC converter and its control. This thematic involves power conservation, safety and intuitive response of the system for human interaction.

\section{Project and design}

\section{a) DC-DC converter}

A switched DC-DC power converter is the natural solution to achieve energy conservation and low power dissipation. To choose the topology of the converter is necessary to know the motor operation demands. Operation demands include vehicle movement forward and back with positive 
or negative force originated by the motor. For that, four operation quadrants are defined in a current/voltage plan (I and $\mathrm{U}$ respectively) from the point of view of the converter, or in a torque/angular speed plan ( $\mathrm{T}$ and $\omega$ respectively) from the point of view of the motor, as displayed in the Fig. 3, [1].

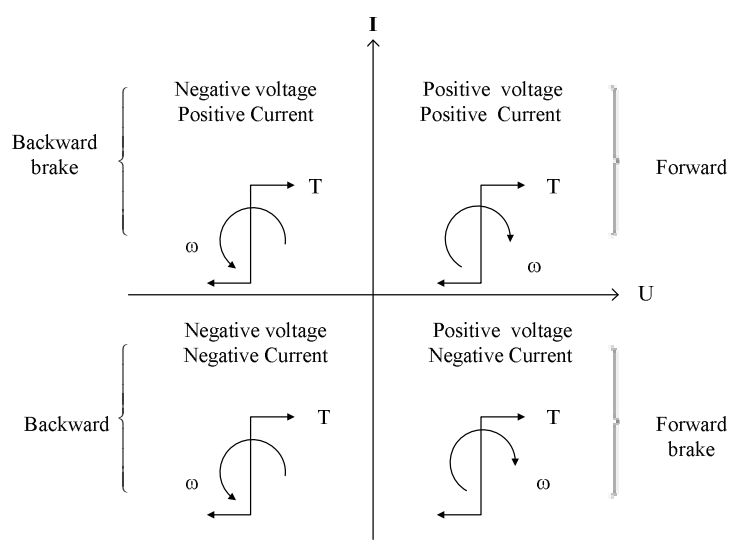

Fig. 3 - Operation in 4 quadrants.

A full bridge converter has been chosen. It operates in the four quadrants and it is possible to control the value and the polarity of the output voltage $\left(\mathrm{V}_{\text {OUT }}\right)$. The power flow can have two ways (from the batteries to the load or from the load to the batteries).

For safety purposes it was adopted $\mathrm{V}_{\mathrm{IN}}<50 \mathrm{~V}$. In this voltage range MOSFETS presents the best solution for switch implementation. The Fig. 4 presents this solution.

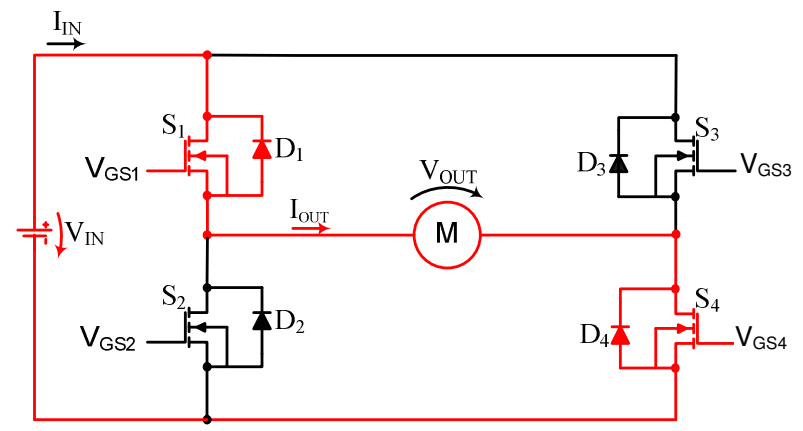

Fig. 4 - Full bridge converter.

The switches $\mathrm{S}_{1} / \mathrm{S}_{4}$ and $\mathrm{S}_{2} / \mathrm{S}_{3}$ are actuated by two complementary signals.

Due the existence of transition times between on and off states of real switches, the short circuit is prevented by the gate drive circuit, that assures a delay time between the command $\mathrm{S}_{1} / \mathrm{S}_{4}$ and $\mathrm{S}_{2} / \mathrm{S}_{3}$ signals [2].

The Fig. 5 shows the transistors gate/source voltage waveforms, $S_{1}$ and $S_{2}$, with the time delay inserted.

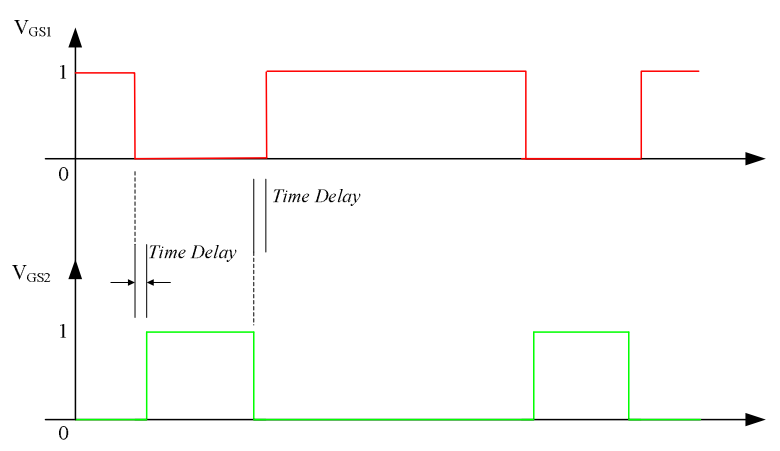

Fig. 5 - Example of gate/source voltage waveforms with time delay included.

The high currents in cause (200A) and the stray inductances presented in the circuit causes high voltage transient peaks when the transistors switch. Consequently the maximum drain source voltage could be exceeded. To avoid this problems a snubber circuit must be used.

To understand the effects of the stray inductances present in a real converter, some simulations have been made. These simulations help to understand the principal causes of problems and also ways to minimise them. The presence of a stray inductance between the batteries and the DC-DC converter is the major source of problems. The Fig. 6 presents the simulation circuit.

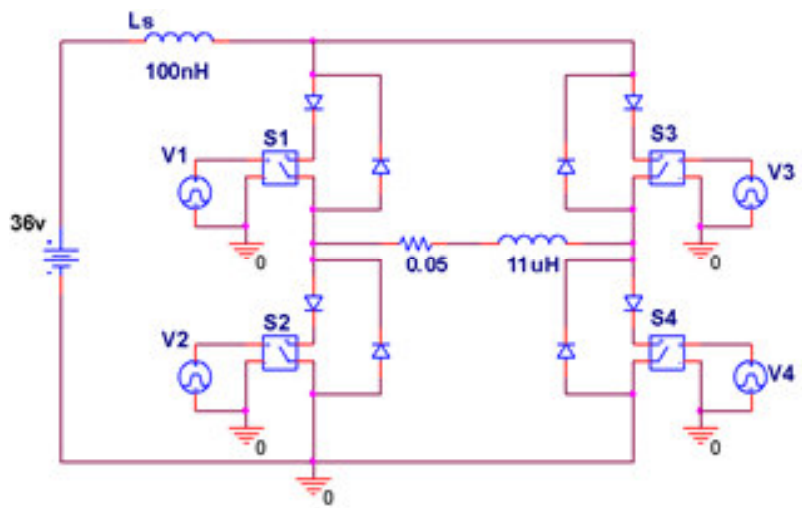

Fig. 6 - Full bridge converter simulation circuit.

The simulation circuit is a full bridge converter operating with a $\mathrm{D}=0,2$ in $\mathrm{S}_{1} / \mathrm{S}_{4}\left(\mathrm{D}\right.$ - duty-cycle, $\left.\mathrm{t}_{\mathrm{on}} /\left(\mathrm{t}_{\mathrm{on}}+\mathrm{t}_{\mathrm{off}}\right)\right)$ and supplied with $36 \mathrm{~V}$. This circuit includes a $100 \mathrm{nH}$ stray inductance, Ls, between the battery and the switches; the load is a RL circuit with $0,05 \Omega$ and a $11 \mu \mathrm{H}$ inductor (equivalent model of the used DC motor, when stopped) the voltage sources V2, V3, V4 and V5 are the command signals of the switches.

The Fig. 7 shows the voltage waveform present in $S_{3}$. 

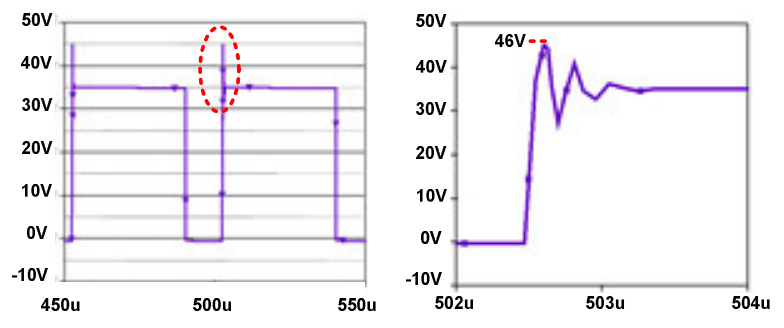

Fig. 7 - Voltage waveform on $\mathrm{S}_{3}$.

The spike voltage in $\mathrm{S}_{3}$ terminals is greater than $46 \mathrm{~V}$ for $\mathrm{L}_{\mathrm{S}}=100 \mathrm{nH}$. The solutions for this problem consist in minimization of the stray inductance values by minimizing the area inside of the current loop and by putting capacitors in parallel with the voltage source, near the switches. Those techniques also help minimising EMI (Electro Magnetic Interference). Beside these techniques it was necessary to implement snubber circuits for protecting the switches from overvoltages, Fig. 8.

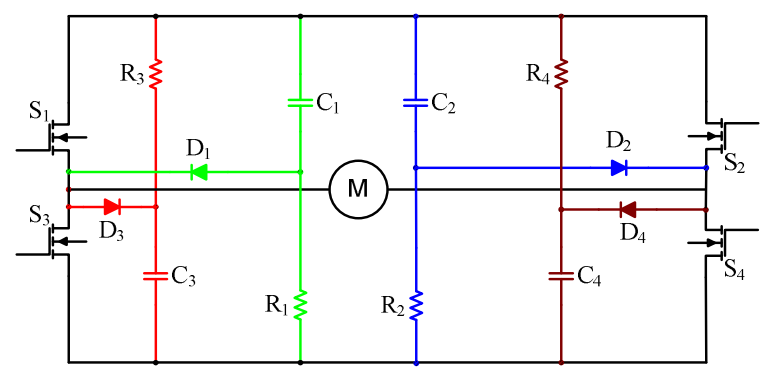

Fig. 8 - Overvoltage snubber circuits.

Considering the snubber elements, C, R and D, and $\mathrm{S}_{3}$ switch, Fig. 9, we have the following principle of operation: during $\mathrm{S}_{3}$ conduction time, the voltage on the capacitor is $V_{\text {IN }}$ guaranteed by the resistor $R$; when $S_{3}$ open, if the drain-source voltage in $S_{3}$ is greater than $V_{I N}, D$ conduces. The overvoltage obtained in $\mathrm{C}$ will be dependent of the stored energy into the stray inductance and of the capacitor value. An approximately value for $\mathrm{L}_{\mathrm{S}}$ can be obtained based on the drain-source overvoltage when the circuit operate without the snubber [3]. In our prototype we use a $2,2 \mu \mathrm{F}$ for $\mathrm{C}$ capacitor and $10 \Omega$ for R. The Fig. 9 shows the overvoltage attenuation, when the overvoltage snubber circuit is used (simulation results).

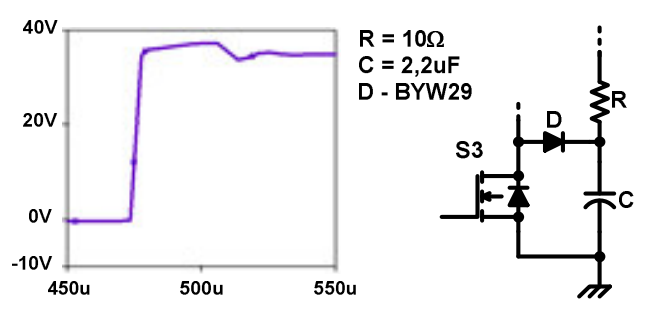

Fig. 9 - Voltage waveform on $S_{3}$ with overvoltage snubber.
Resistances of $\mathrm{m} \Omega$ present in the circuit (cables, MOSFETS $\mathrm{R}_{\mathrm{DSon}}$ and inductor resistances) produce heat and losses. Those factors have to be taken in consideration in the design and construction phase, for assuring reliable operation.

\section{b) Filter}

The motor self-induction coefficient is very low $(11 \mu \mathrm{H})$. Therefore the introduction of an external inductance, L, (in series with the motor) is indispensable to increase the total inductance, avoiding high ripple currents. This inductance must support the output current, $\mathrm{I}_{\text {out }}$, without significant losses. It isn't possible to use an LC filter, because the parasitic elements present in a capacitor, Equivalent Series Resistor (ESR) and Equivalent Series Inductance (ESL), results in high losses.

To design the inductive filter, $\mathrm{L}$, the inductance of the motor, $\mathrm{L}_{\mathrm{M}}$, must be considerated. The total inductance, $\mathrm{L}_{\mathrm{T}}$, present in the circuit corresponds to the sum of this two inductances. The Fig. 10 shows the inductive filter and the equivalent circuit of the DC motor. The E represents the inverse electromotive force produced by the motor.

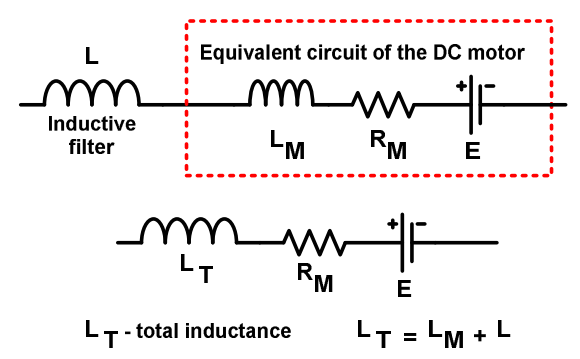

Fig. 10 - Inductive filter and the equivalent circuit of the DC motor.

The current ripple in the motor is given by the equation 1 :

$$
\Delta \mathrm{i}_{\mathrm{L}}=\frac{\Delta \mathrm{v}_{\mathrm{L}}}{\mathrm{L}_{\mathrm{T}}} \Delta \mathrm{t}
$$

The criteria's of the $\mathrm{L}$ inductance design are related with the maximum $\Delta_{\mathrm{iL}}$ and the $\Delta_{\mathrm{T}}$. The $\Delta_{\mathrm{T}}$ is dependent of the transistors switching times, which are defined by the current control circuit. Consequently, the inductance value is defined in the control section.

To determinate the inductance $\mathrm{L}$, there was used the area-product method [4]. For this dimensioning method it was necessary to define: the ferrite core area, the area that can be filled with copper wires and the size of the core-gap. The Fig. 11 presents drawings of these dimensions. 


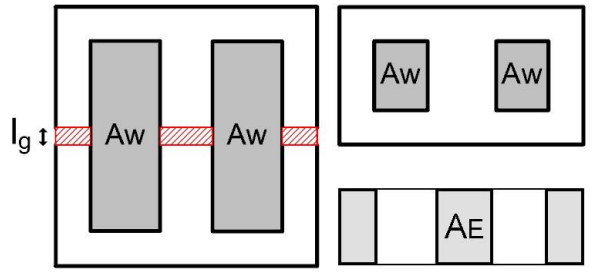

Fig. 11 - Representation of Aw, AE and $\mathrm{l}_{\mathrm{g}}$ for inductance design.

Where:
AE - area of the ferrite core;
Aw - area that can be filled with copper wires;
$1_{\mathrm{g}} \quad$ - length of the core-gap.

The number of turns is given by:

$$
\mathrm{N}=\frac{\mathrm{LI}_{\mathrm{Lmax}}}{\mathrm{B}_{\max } \mathrm{A}_{\mathrm{E}}}
$$

Where:

$\mathrm{N} \quad$ - Number of turns;

Bmax - Maximum magnetic induction;

ILmax - Maximum current in the inductance;

$\mathrm{AE} \quad$ - Area of the ferrite core.

For the values of current in cause there was some difficulty in finding a ferrite core that allows the sufficient inductance and simultaneously avoid saturation. The inductance dimensioning is based in E 55/28/21 ferrite material.

\section{c) Control}

The output current of the converter is the variable to be controlled. This type of control is better than a voltage control for two main reasons:

1) It obtains an intuitive correspondence between throttle control and the torque applied. An action in the throttle control of the vehicle should have direct correspondence in the torque applied by the electric machine, as is obtained on an vehicle equipped with an internal combustion motor;

2) It protects the motor, electronic power converter and mechanics. If the current is not controlled, the limits of the several electric and mechanic components can be surpassed with possible destruction of the equipment and consequently causing injuries to the passengers.

The current control can be implemented by several methods. The chosen one was sliding mode control, essentially due to the following advantages:

1) Well adapted to the discreet characteristic of the switching signal;
2) Simplicity of design and implementation;

3) Capacity to maintain the current error limited in a pre-defined band (hysteretic band), through control of the on and off states of the switches.

The output voltage of the switched converter could be in two possible voltage levels: $+\mathrm{V}_{\text {IN }}$ or $-\mathrm{V}_{\text {IN }}$. The sliding mode controller commands the transition between those two levels. The difference between the current reference and the real value is used to decide the future state. If the current is higher than a hysteretic value, $i_{m}$, the system changes of state. Consequently the maximum and minimum current value allowed in the DC motor is $\mathrm{I}_{\mathrm{ref}}+\Delta \mathrm{i}_{\mathrm{m}}$ and $\mathrm{I}_{\mathrm{ref}}-\Delta \mathrm{i}_{\mathrm{m}}$, making a hysteretic band $\left(\mathrm{I}_{\mathrm{ref}} \pm \Delta \mathrm{i}_{\mathrm{m}}\right)$. The current will always be between these two values. The Fig. 13 shows the temporary evolution of the motor current to an abrupt request of the reference signal $\left(\mathrm{I}_{\mathrm{ref}}\right)$ [5].

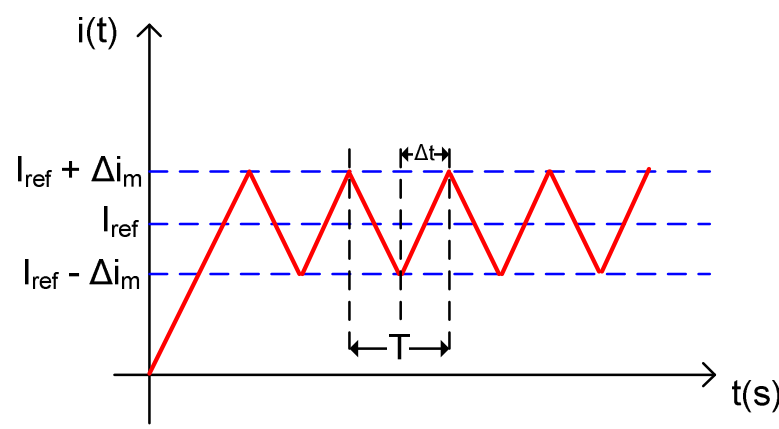

Fig. 12 - Evolution of the motor current in sliding mode control.

In a steady-state operation, the current signal is periodic with period $\mathrm{T}$. The allowed current change is the hysteretic band and the current changes from $\mathrm{I}_{\text {ref }}-\Delta \mathrm{i}_{\mathrm{m}}$ to $\mathrm{I}_{\mathrm{ref}}+\Delta \mathrm{i}_{\mathrm{m}}$ in the period $\Delta \mathrm{t}$.

The Fig. 14 shows the building blocks diagram of the control system:

1) The throttle pedal gives the reference signal (current to be achieved);

2) A current probe gives the signal of the current in the motor;

3) The error calculator makes the difference between reference signal and the current probe signal;

4) The comparator allows a hysteretic error value to be reached and then switches the output value, generating a command signal;

5) The power converter switches $V_{\text {OUT }}$. 


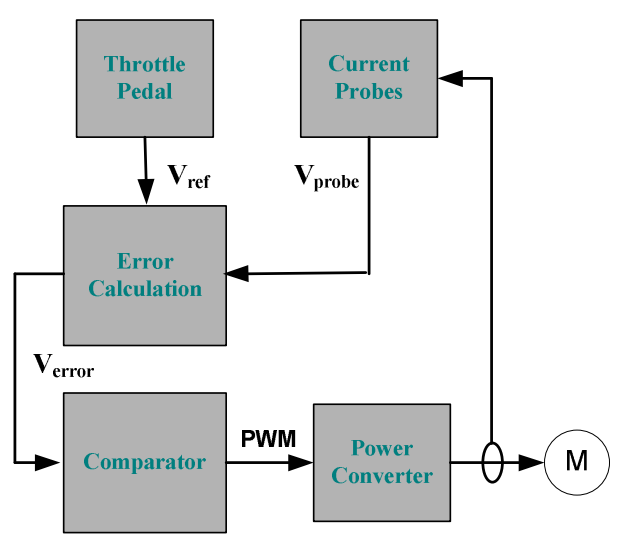

Fig. 13 - Building blocks of the sliding current control.

Sliding current control has variable switching frequency operation. The maximum switching frequency occurs when the duty-cycle is $50 \%$ and the motor is stopped. Using equation 1 , is possible to obtain the maximum switching frequency, $\mathrm{f}_{\text {Smax }}$ :

$$
\mathrm{f}_{\mathrm{Smax}}=\frac{\mathrm{V}_{\mathrm{IN}}}{\mathrm{L}_{\mathrm{T}} \Delta \mathrm{i}_{\mathrm{L}}}
$$

For dimensioning $\mathrm{L}_{\mathrm{T}}$ a hysteretic current band of $25 \mathrm{~A}$ was considered admissible (about $12,5 \%$ of the nominal current of the motor). The maximum frequency considered was $30 \mathrm{kHz}$ (above $20 \mathrm{KHz}$ to avoid audible noise and not too high to avoid elevating to much the switching losses). Equation 3 gives an $\mathrm{L}_{\mathrm{T}}$ value of $48 \mu \mathrm{H}$. Consequently the $\mathrm{L}_{\mathrm{T}}$ value is $37 \mu \mathrm{H}$.

\section{d) Gate drive circuit}

The command signal produced by the sliding control is one square wave signal. To produce the command signals to the four transistors of the full bridge (with adequate gate/source voltages and timings) there was necessary the use a circuit driver. The option is the IC IR2110. This circuit uses a bootstrap capacitor to produce a voltage higher than $V_{\text {IN }}$, necessary to actuate the upper side switches $S_{1}$ and $S_{3}$. The time delay is produced with logic circuits and RC networks.

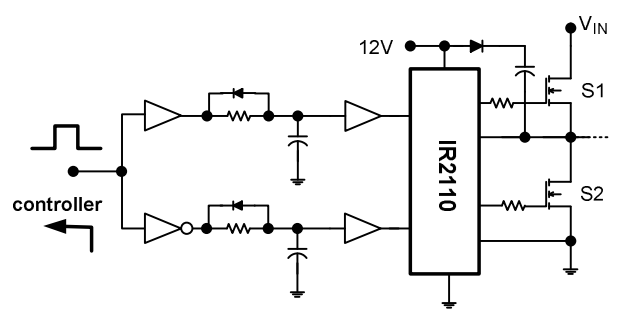

Fig. 14 - Half-bridge gate drive circuit.

\section{Implementations and tests}

\section{a) Implementation}

The electrical machines used in this project are two LEM 230 motor, manufactured by LMC. They are direct current (D.C.) motors, with axial brushes, appropriate for traction in EV's and industrial applications, see Fig 16.

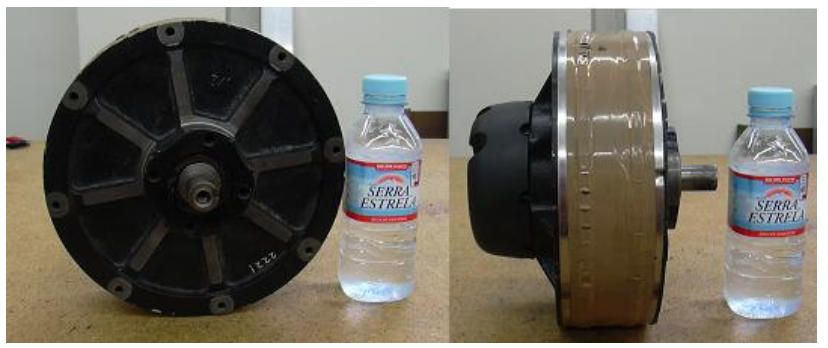

Fig. 15 - Motor LEM 230.

Three 12V batteries Optima Yellow Top with 55Ah capacity were used in a series connection.

The DC/DC power converter contains the MOSFET's IRFP2907 (two in parallel for each switch) for $75 \mathrm{~V}$ and 209 A absolute maximum ratings operation.

During the implementation of the DC-DC converter there were several problems due to the high current value needed and parasitic elements that causes non-desirable effects. It is important to take in consideration that the current ripple in the input of the converter is twice the average output current. Consequently the copper buses used to solder the transistors and build the converter have to be of considerable dimensions, as can be seen in Fig. 17. They were attached to a Celeron plate to assure physic stability. The buses dispositions have been studied to minimize undesirable stray inductances. Fig. 17 also represents the low ESR capacitors mounted in parallel with the voltage source and near the switches to reduce stray inductance effects.

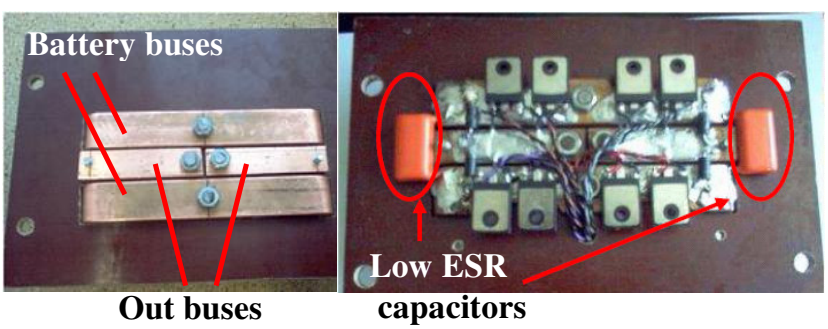

Fig. 16 - Bottom view of copper buses used for converter implementation: before and after component soldering.

The fig. 18 shows the $10.000 \mu \mathrm{F}$ electrolytic capacitors, to provide a low voltage ripple in the buses, and snubber circuits. 


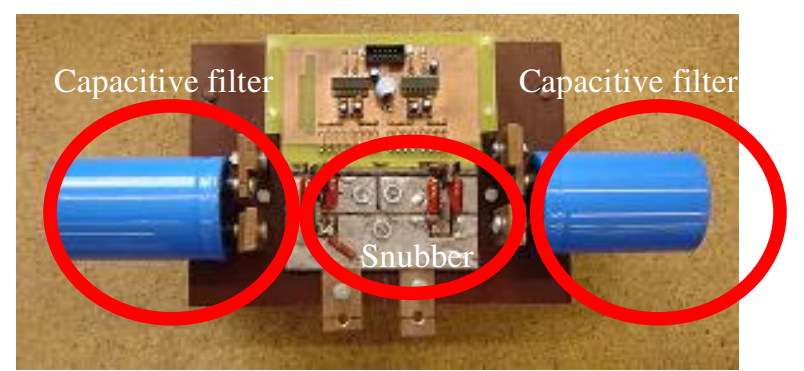

Fig. 17 - Converter with snubber and capacitive filter.

The design of the $\mathrm{L}$ inductance has two competing targets: minimum size and minimum losses. The Ohmic losses vary with the square of the current $\left(\mathrm{P}=\mathrm{R} \cdot \mathrm{I}^{2}\right)$. Due the high values of current in the inductance (up to 200A) the losses can easily reach considerable values (in spite of extremely low resistance, in the order of the $\mathrm{m} \Omega$ ) [6].

The high diameter of the wire that is needed, make it very rigid, creating an obstacle to the execution of the coil. The used strategy is to put several wires in parallel (six wires were used). With these values and considering the areaproduct method it was necessary to use 5 individual cores grouped together achieving $33 \mu \mathrm{H}$ and $2.2 \mathrm{~m} \Omega$, see Fig 19.

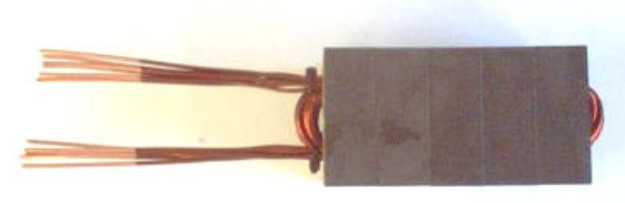

Fig. 18 - Build inductance

The efficiency of the power converter is relatively high, with conducting losses being usually higher then switching ones. The total equivalent resistance presented by the fullbridge, due to the $\mathrm{R}_{\mathrm{DS} \text { on }}$ of the transistors, is only of about $4.5 \mathrm{~m} \Omega$. Power dissipation due conducting losses is about $180 \mathrm{~W}$ at $200 \mathrm{~A}$.

\section{Experimental results}

The Fig. 20 shows the waveforms of the motor current (triangular waveform) and of the output voltage (square waveform) provided by the optimised converter for three different duty cycles.

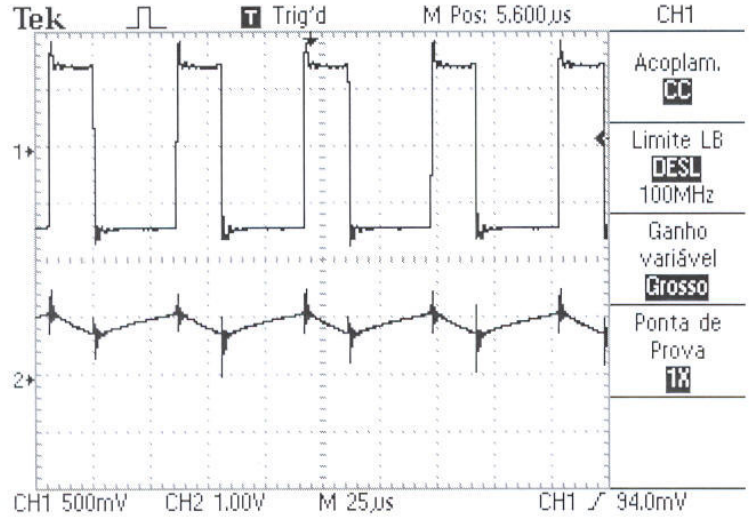

(a) $\mathrm{CH} 1-25 \mathrm{~V} / \mathrm{div}, \mathrm{CH} 2-50 \mathrm{~A} / \mathrm{div}$

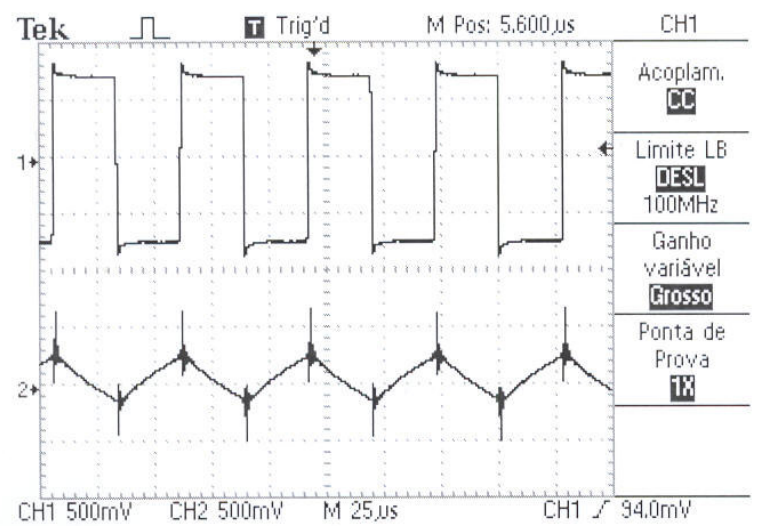

(b) $\mathrm{CH} 1-25 \mathrm{~V} / \mathrm{div}, \mathrm{CH} 2-25 \mathrm{~A} / \mathrm{div}$

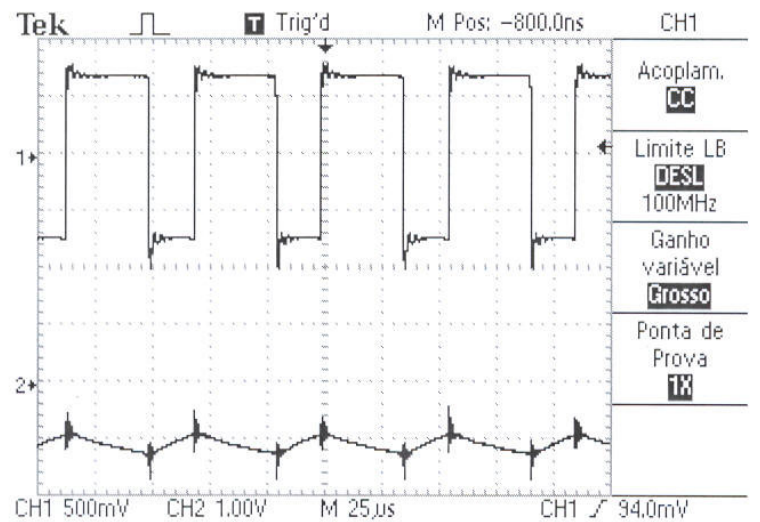

(c) $\mathrm{CH} 1-25 \mathrm{~V} / \mathrm{div}, \mathrm{CH} 2-50 \mathrm{~A} / \mathrm{div}$

Fig. 19 - Output voltage converter and inductance current for different duty cycle values; (a) $\mathrm{D}=0,3$; (b) $\mathrm{D}=0,5$; (c) $\mathrm{D}=0,7$.

Fig. 21 show the completed system implemented and mounted in the vehicle. 


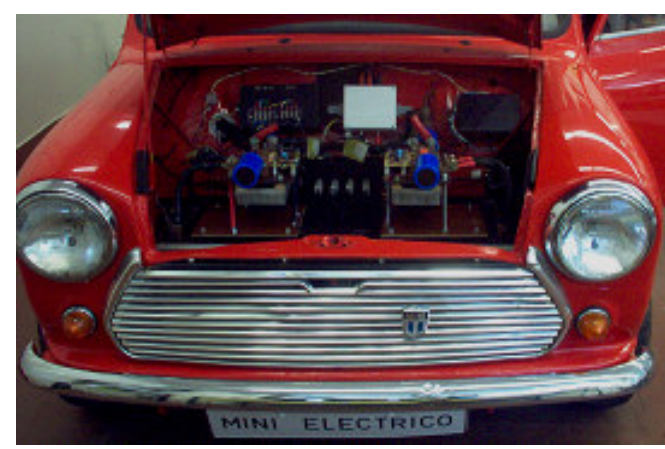

Fig. 20 - Implemented system in the vehicle.

\section{Conclusions}

The real implementation of the two power converters and the respective current control for two DC motors arises several questions due to the high currents in cause: overvoltages at the switching transitions, power dissipation in cables, EMI and filter design. To avoid high current ripple it was necessary to design and construct an inductance, which is also problematic (due to the some reasons already referred). All those problems where surpassed by evaluation of the system limitations, careful design and implementation.

The current control method used allows auto-protection for some faults: blocked wheels, unequal torque produced by the two motors when the car is turning (what happens if a voltage control is used). Another advantage is the intuitive response of the vehicle obtained when actuating the throttle control, similar to the internal combustion engine normally used by the majority of the population.

The objective of this paper is to evaluate solutions for the power converter and control. Other subjects where addressed in this project: like protection circuits, mechanics, etc. but they aren't focused here.

With the present realization, the author's objective is to make a small contribute to achieve noise and pollution free cities. The following picture shows the final result of this project: the "electrical mini", during a test drive.

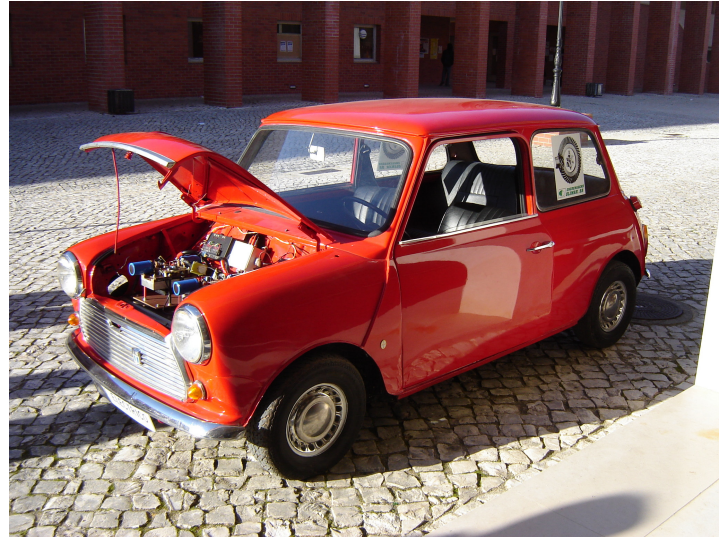

Fig. 21 - The vehicle ready to roll.

\section{6. $\quad$ References}

[1] Palma, J. C., "Accionamentos Electromecânicos de Velocidade Variável”, Fundação Calouste Gulbenkian, 1999

[2] Bose, Bimal K., "Power Electronics and Variable Frequency Drives", IEEE, ISBN 0-7803-1084-5

[3] Mohan, Ned, "Power electronics “ John Wiley \& Sons, Inc. ISBN 0-471-58408-8

[4] Guilherme, Jorge, "Critério de Dimensionamento de Bobinas e Transformadores", 2003

[5] Roque, António Eusébio Velho, "Contributos para um controlo de tracção de um veiculo eléctrico bimotor", Master thesis, 2001

[6] Santos, Rui and Pais, Fernando, Project Report, "Desenvolvimento de um Conversor de Potência", 2006 